\title{
Presentación de Paul Tillich (1886 - 1965)
}

Introducción. I.- Epoca de preparación (1886-1918): la familia, experiencia religiosa, proletariado y experiencia de la guerra, formación universitaria. II.- La vida en plenitud (1919-1965): Socialismo Relligioso, 'la emigración, magisterio americano, producción tillichiana. III. El sistema: método, fuentes de la teología, elemento mediador, el criterio teológico.

\section{INTRODUCCION}

En la tarde del 22 de octubre de 1965 moría Paul Tillich, de un infarto de miocardio, en una clínica de la Universidad de Chicago, a la edad de 79 años. Momentos antes había pedido perdón a su esposa por todo aquello que hubiera podido apenarle a través de su largos años de matrimonio; recitaron juntos un pequeño poema alemán, muy querido de ambos, y expiró. En la mañana de este mismo día había repetido: This is may dying day. Las emisoras oficiales de televisión interrumpieron sus programas para, "después de unos minutos de silencio, dar la noticia". Aquella misma noche más de trescientos estudiantes universitarios formaron espontáneamente una procesión de antorchas ante la clínica universitaria. Era la despedida al maestro. Pocos meses antes de su muerte, habian 
acudido a escucharle más de siete mil en la Universidad de Berkeley (California) ${ }^{1}$.

Sus restos mortales fueron trasladados ocho meses más tarde a New-Harmony (Indiana) para ser depositados definitivamente en el Paul Tillich-Park, fundación y recuerdo de Jane Owen ${ }^{2}$ Era el final de una larga vida y de un trabajo continuado. Final coronado de reconocimiento y aplauso, pero madurado en el esfuerzo, en la lucha, en la incomprensión y en muchas contradicciones. Era el final de un hombre extraordinario y agraciado "que había recibido de Dios la capacidad de escudriñar y dominar toda la historia del pensamiento" ${ }^{3}$. El mundo de la cultura le rindió homenaje de admiración y agradecimiento, ya que mediante su magisterio "Tillich ha hecho posible a innumerables hombres modernos ser o seguir siendo cristianos sin dejar de ser hombres modernos". La obra de su vida tuvo una única finalidad: "exponer al hombre de hoy el cristianismo como cumplimiento de toda religión, librando de obstáculos el camino que lleva a él, y mostrar e el panorama de un subyugador sentido. La raíz de la fe era para él simple y fundamental" ". Su importancia como cristiano, como hombre de cultura y como maestro ha sido reconocida por doquier ${ }^{5}$.

Seguir de cerca el carisma extraordinario de este hombre no es tarea fácil. Nuestro objetivo en esta presentación es más sencillo: penetrar en el aíma de Tillich, analizando los pasos más sobresalientes y más personales de su exisiencia. Debemos confesar, co-

1. J.C. BRAUER, "Paul Tillich's Impact on America", en The Future of Religions, New York 1966, p. 15; Cfr. O. HaEndLen, Werk und Wirken Paul Tillichs, Stuttgart 1967, p. 67: (Trad. española: Paul Tillich. Su obra y su influencia, Madrid 1971).

2. R. May, Paulus, A personal Portrait of Paul Tillich, London 1974, pp. 105-106. Fue el mismo Tillieh el que manifestó en viđa su voluntad de ser enterrado en ese lugar. New Harmony es un pequeño poblado en el Estacio de Indiana, convertido actualmente en recuerdo y monumento a una utopía:fue el refugio de unos emigrados centro-europeos que ensayaron un modo de vida socializada, teniendo como principio fundamental el "trabajar todos para todos". Cfr. R. Rertz, Paul Tillich und New-Harmony, Stuttgart 1970.

3. O. HaENDLER, Werk und Wirken Paul Tillichs, Stuttgart 1967, p. 49. 69.

4. O. Haendlen, Werk und Wirken Paul Tillichs, Stuttgart 1967, pp. 68-

5. B. Mondin, filósofo católico y alumno de Tillich en Harvard, escribe: "Toaay Tillich is one of the most prominent Protestant Theologians. In America his influence is stronger than that of any Catholic or Protestant theologian" (The principle of analogy in Protestant and Catholic Theology, The Hague 1967, p. 118). 
mo ya han señalado a!gunos de sus comentadores, que la vida y el pensamiento de Tillich son inseparables. Su pensamiento y su vida se confunden: ambos vienen a ser una consecuencia de su encuentro y de su interpretación cristiana con el mundo y el hombre de hoy. Debemos confesar también que no es nuestro intenio el hacer una introducción general más, comentando su vida y sus escritos. Son varias las ya realizadas hasta nuestros dias ${ }^{6}$.

A través de los diversos apartados procuraremos, a la vez que seguir la huella de sus días, descorrer el velo de su misterio personal, tratar de encontrar su humanidad profunda, mezcla de grandeza y de pobreza, su espíritu abierto a todo, su mente atormentada por la verdad que le lleva a buscar la gran síntesis, como servicio actual al mensaje siempre eterno del evange'io: "En una época en que bajo la égida de $K$. Barth y sus amigos, la teología y la Iglesia Protestante se habían distanciado radicalmente de a filosofía y de la cultura, y se había sostenido la diástesis entre Dios y el hombre, entre revelación y religión, entre fe y pensamiento filosófico, Paul Tillich fue uno de 'os pocos protestantes que se empeñó en la sintesis, que afirmó la unicidad de la verdad y que puso a la fe en contacto con el pensamiento, el mundo y la cultura" ?

Un discípulo de $K$. Barth comenta: "Certainly today Paul Tillich represents one of the two or three most distinct and important directions of contemporary theology" (A. J. MCKELWAY, The systematic Theology of Paul Tillich. A revew and analysis, New York 1964, p. 19).

El P.. Weigel, una de las figuras más representativas de la teologia católica americana, afirma: "This man (Tillich) is most significant for Theology in contemporary West. It can be maintained without rashness that he is the most impressive figure in today's Protestant Theology, which is distingued by many great names both in Europa an America" (The theological Significance of Paul Tillich", en Gregorianum 37 (1956), n. 1, p. 48).

6. Las publicaciones españolas sobre Tillich son muy escasas hasta la actualidad. De ahi mi decisión de ofrecer al público de habla hispana esta Presentación, que bien puede servir como orientación previa a toda lectura de Tillich. Entre las principales introducciones realizadas en otros idiomas sobre Tillich podriamos recoger las siguientes: J. L. ADAMs, Paul Tillich's Philosophy of Culture, Science and Religion, New York 1965, pp. 116 ; G. H. TAVARd, Paul Tillich and christian Message, New York 1962, pp. 114 ; J. H. Thomas, Paul Tillich: an appraisal, London 1963, pp. 9-19; G. B. HAMOND, The Poue of self-trancendence, St. Louis 1966, pp. 15-33; J. ScHMirz, Die Apologetische Theologie Paul Tillichs, Mainz 1966, pp 1-11; $\mathbf{E}$. ScABINI, Il pensiero de Paul Tillich, Milano 1967, pp. 7-30; B. Mondin, Paul Tillich e la transmitizzazione del Cristianesimo, Torino 1967, pp. 15-40; J. $P$. Gabus, Introduction a la Théologie de la Culture de $P$. Tillich, Paris 1969, pp. 1-14; C. J. Ambruster, The vision of Paul Tillich (Trad. española: El pensamiento de P. Tillich, Santander 1968, pp. 21-59). p. 98 .

7. U. NEUENSCHWANDER, Werk un Wirken Paul Tillichs, Stuttgart 1967, 
I: EPOCA DE PREPARACION (1886-1918)

Nació en 1886, el 20 de agosto, en Starzeddel, un pequeño pueblo de la provincia de Brandeburg, en la parte oriental de Alemania. Su padre era pastor de la iglesia territorial prusiana, en cuya región había nacido. Su madre era de la Renania. Cuatro años después, la familia se traslada a Schönfliess, al ser nombrado el padre superintendente de la diócesis de Schönfliess-Neumark, viviendo de lleno el ambiente protegido de una pequeña ciudad de tipo medieval. Los dos años pasados en Könisberg (1898-1900) como alumno del Gymnasium no cambian en nada el panorama de la vida del joven Tillich. En 1900 su padre es llamado a ocupar un alto puesto en la administración de la iglesia territorial prusiana, en Berlín, terminando. Tillich aquí el Gymnasium en 1904. Durante ocho años (19041912) frecuenta Tillich los cursos de tología y filosofía en las universidades de Berlín, Tübingen y Halle, obteniendo el doctorado en filosofía en Breslau (1910) y la licencia en teología en Halle (1911); con trabajos sobre Schelling. Después de pasar dos años como vicario parroquial, se enrola voluntariamente como capellán del ejército alemán en la primera gran guerra mundial (septiembre 1914 a septiembre 1818) ${ }^{8}$.

LA famrira.- Paul es el hijo mayor del matrimonio. Sus hermanas Johanna y Elisabeth son cuatro y siete años más jóvenes que él. Su padre, según confesión de la misma esposa de Tillich, Hannah, era un "hombre rudo pero agradable, del que siempre se aprendía algo, a pesar de su carácter autoritario"? El mismo Tillich recuerda

8. El mismo Tillich nos ha dejado diversos ensayos auto-biográficos que facilitan el hilo de su vida, tanto a nivel cronológico como a nivel espiritual. He aqui los principales: On the Boundary. An autobiograprical Sketch, New York 1964. Este ensayo, aunque un poco corregido, es la primera parte del libro con que Tillich se presentó al público americano The Interpretation of History, . New York 1936; "Autor's Introduction" a The Protestant Era, Chicago 1948, en donde Tillich analiza fundamentalmente su formación teológica; "Autobiographical Reflections" en The Theology of Paul Tillich, New York 1952, de rico contenido personal sobre su actividad académica en Alemaniá y en América hasta esa fecha; "The Conquest of intellectual Provincialism: Europe and America". en Theology of Culture, New York 1959.

9. R. MAY, Paulus. A personal Portrait of P. Tillich, London 1974, p. 37: 
las restricciones sociológicas y psicológicas de los años de su niñez; restricciones basadas en la estructura de la sociedad prusiana del Este, de la cual su padre era un representante nato. "El paternalismo luterano hacía del padre el jefe indiscutible de la familia que incluía, en la casa de un ministro de la iglesia, no solamente la mujer y los hijos, sino también los diversos servidores" 10 .

Fruto de este ambiente autoritario prusiano es el entusiasmo que Tillich manifiesta en sus primeros años por las paradas militares, las historias bélicas y los uniformes militares. Entusiasmo que conservó hasta las brutales experiencias de la guerra: "Se hizo necesario una guerra muncial y una catástrofe política, antes de que yo fuera capaz de romper con este sistema de autoridades y poder afirmar la creencia en los ideales democráticos y en la revolución social" i1.

El recuerdo que Tillich mantiene de su padre es siempre el mismo: autoritario y conservador: "mi padre era un hombre pensativo, muy austero, plenamente convencido $y$, ante cualquer duda, defensor acérrimo del punto de vista luterano-conservador". Semejante postura paterna se acentúa en el campo religioso e intelectual, llegando a provocar en Tillich la conciencia de pecado cada vez que, de alguna manera, se oponia a su padre. Sacudirse el peso de la autoridad paterna, de marçado carácter heterónomo, fue para él un camino largo y difícil. "Siguiendo la tradición de la ortodoxia clásica, mi padre amaba y usaba la filosofía, convencido de que no era posible que existiera conflicto alguno entre la verdadera filosofía y la verdad revelada. Las largas discusiones filosóficas que se desarrollaron entre nosotros fueron los momentos más felices en la relación que tuve con mi padre. No obstante, durante estas discusiones se llevó a cabo también la ruptura. Partiendo de una postura filosófica independiente, se afirmó en mí en todas direcciones un estado de independencia, en principio teórico y después práctico. Este camino difícil y penoso hacia la autonomía ha sido el que me ha hecho inmune a cualquier sistema de pensamiento o a cualquier forma de vida que exija la renuncia a esta autonomía" ${ }^{12}$

Este carácter dominante del padre, acentuado por la temprana

10. The Theology of P. Tillich, New York 1952, p. 7.

11. The Theology of $P$. Tillich, p. 8 .

12. The Theology of $P$. Tillich, p. 8. 
muerte de la madre, condiciona psicológicamente la vida de Tillich y explica; en parte, su lucha decidida contra todo tipo de autoritarismo, así como contra toda impostación doctrinal de carácter absolutista: religiosa, política, social o histórica. El mismo. Tillich confiesa que sin tener en cuenta estas primeras influencias es difícil comprender su vida ${ }^{13}$.

En contraste con el padre, su madre, de origen renano, carecía de las actitudes autoritarias del padre, aunque "seguía bajo el influjo de la rigidez moral del Protestantismo Occidental Reformado" ${ }^{14}$. En contraste también con el oriente prusiano, el occidente renano se hace notar por su intuición y viveza, su alegría ante la vĩda y su amor a la democracia. En el ensayo psicológico-biográfico de Rollo May, la madre de Tillich aparece como una mujer cuya fuerza reside en su capacidad de crear en torno a sí un clima de afecto, convirtiéndose de esta manera en "el poder detrás del trono" ${ }^{15}$.

Un cierto puritanismo externo había de ser mantenido. Cualquier manifestación infantil del impulso sensual debía ser reprimida y guardada en silencio; haciéndose necesaria una transposición al mundo de la fantasía y de la razón. De esta forma, la inteligencia y la sensibilidad del joven Tillich absorbieron el ardor sexual adolescente, provocando seguramente un retraso considerable en la maduración afectiva y erótica. La madre murió de cáncer cuando Paul tenía 17 años (1903), produciendo en el joven una experiencia profunda de abandono y soledad, a la vez que le provocaba una seria crisis de identidad. Conservamos un poema escrito por el mismo Tillich a raíz de la muerte de la madre:

¿Existo realmento yo? ¿Quién me dice que yo existo! ¿Quién me dice lo que yo soy, lo que yo seré? ¿Cuál es el sentido del mundo y de la vida? ¿Qué es el existir y el pasar sobre la tierra? iOh abismo sin fondo, de locura oscuridad profunda! Nunca te había contemplado fijamente Y dormía como un niño! ${ }^{16}$.

Sin haber salido todavia de la adolescencia, el joven Tillich se

13. On the Boundary, pp. 14-15.

14. The Theology of $P$. Tillich, p. 8.

15. R. May, Paulus. A personal. Portrait of P. Tillich, pp. 37-38.

16. R. MAY, Ib. p: 41 . No es de extrañar que el célebre psicoanalista americano conserve éste y otros muchos detalles de Tillich, ya que fueron amigos desde 1934. Según confesión del mismo $R$. May, Tillich vino a ser 
pregunta por el sentido de la vida por lo que es, por lo que será, por el sentido del mundo y de la muerte. El punto de apoyo - su madresobre el que hasta el presente se habia apoyado no existía ya Sin faro que le ilumine, la ausencia de la madre le abre al abismo de la angustia, de la responsabilidad, de la historia y de su propio yo. Recordando aquellos años escribe: "El equilibrio y la armonía no formaron parte de mi herencia Aquí radican también algunos presupuestos psiquicos de mi interpretación de la historia: la defensa de la línea progresiva que se dirige hacia algo, frente a la línea circular clásica que se cierra en sí mismá; el planteamiento de dos principios contradictorios, cuya lucha constituye el contenido de la historia; la teoría de la verdad dinámica, según la cual la verdad es en si misma lucha y destino y no un ser inmóvil 'más allá del destino, como en Platón" "it.

El dinamismo vital tillichiano está marcado por el signo de la tensión, expresado bellamente en el concepto de "frontera" (on the boundary). Tensión entre el padre y la madre; entre la Prusia y la Renania; entre el autoritarismo y la autonomía; entre la lucha y el destino; entre el romanticismo y la revolución. El destino y el deber surgen en Tillich como consecuencias de estas primeras motivaciones familiares, configurando su carácter y sus trabajos: "su existencia era semejante a la de un hombre que conduce una bicicleta y que conserva su equilibrio mediante el movimiento siempre hacia adelante" "18. Vivió en la frontera entre la experiencia y el pensamiento; entre la patria y el exilio no buscado; entre la filosofía y la teología; entre el proletariado y la burguesía; entre la Iglesia y la sociedad; entre la religión y la cultura; entre lo infinito y lo finito; entre la heteronomía y la autonomía, optando siempre por la última en forma teónoma, aunque debiera pagar un fuerte precio por ello: "La experiencia inmemorial de la humanidad de que solamente se pue-

para èi algo así como su "padre espiritual", su ánimador interior y su verdadero amigo. El poema nos lo transcribe $R$. May en su original alemán. La versión española es mía.

Bin ich denn ich, wer sagt mir, dass ich bin!

Wer sagt mir, was ich bin, was ich soll werden

Was ist das Sein und das Vergehn auf Erden?

Was ist der Welten, was des Lebens Sinn?

O Abgrund ohne Grund, des Wahnsinns finstre Tiefe!

Ach dass ich nimmer Dich geschaut

und kindlich schliefe!

17. On the Boundary, p. 15.

18. R. May, Paulus. A Personal Portrait, p." 45. 
de adquirir un nuevo conocimiento mediante la ruptura de un tabú y de que, por tanto, el pensamiento autónomo va seguido de una conciencia de culpabilidad, fue y es una experiencia fundamental en mi vida"' 19

EXPERIENCIA RELIGiósa-- Los años trañscurridos en Schönfliess (1890-1898) y en Könisberg (1898-1900) en torno a una escuela confesional y a una hermosa iglesia gótica, hiciéron nacer en Paul una profunda experiencia personal de lo "sagrado". "La base de este sentimento fue puesta en los años juveniles no sólo por la orientación cristiana de una casa parroquial evangélica, sino también por la costumbre religiosa bastante firme de una pequeña ciudad del este del Elba en las postrimerías del s. XIX. Mi cariño por el edificio de la iglesia y su atmósfera mística, por la liturgia, la música y la predicación, por las grandes fiestas religiosas que determinaban la vida del pueblo durante días y semanas, dejaron un sentimiento indeleble en mi alma hacia lo eclesiástico y lo sacramental". 20.

El lenguaje de las Escrituras, los misterios de la vida cristiana, las experiencias apasionadas de la santidad, de la culpa y del perdón; motivaron su: decisión de hacerse teólogo. Su conciencia de pertenencia a la Iglesia se mantuvo viva a través de los años, como lo denota su ordenación como pastor protestante, su apostolado de capellán militar en la primera guerra mundial, su actividad directamente pastoral en los años que precedieron y siguieron a la gran guerra, su interés por la predicación y por la liturgia durante todo su magisterio en tierras americanas. Tillich recuerda como "experiencia importante" de su vida de alumno universitario la convivencia de las confraternidades. Llegó a ser presidente de la Wingolf (1907): "La fraternidad me ofreció un ambiente (el primero después de la familia) en el cual la amistad, el intercambio espiritual a un nivel alto, la educación directa e indirecta, la alegría de vivir, el compromiso serio con los problemas de la vida comunitaria en general, y de manera especial de la vida comunitaria cristiana, podian ser experimentados a diario. Me pregunto si de no häber tenido esta experiencia, hubiera podido llegar a entender el significado de la Iglesia, existencial y teoréticamente" ${ }^{21}$.

19. On the Boundary, p. 37 .

20. On the Boundary, p. 59.

21. The Theology of P. Tillich, p. 20-21. 
Todo este cúmulo de experiencias religiosas fueron vividas por Tillich en el marco del Iuteranismo, del cual nunca renunció a pesar de haber experimentado en su carne las consecuencias pobres de la ética social luterana: "Yo soy un luterano por nacimiento, educación, experiencia religiosa y reflexión teológica... La sustancia de mi religión es y sigue siendo luterana" ${ }^{22}$.

Tal sustancia luterana incluye, según Tillich, una serie de puntos: la conciencia de una existencia caída en total oposición a toda especie de pelagianismo; el repudio de toda utopía social de tipo progresista que espere un paraíso temporal realizado; el elemento místico de toda religión; la consciencia de la presencia de lo demoníaco y de lo irracional en la existencia, así como el rechazo del puritanismo, tipo calvinista, en la vida personal y social. Este carácter demoníaco, con sus elementos destructores, forma parte del entarimado de la historia y de la cultura. De ahí la posibilidad de que cualquier institución - la misma Iglesia en su perspectiva sociológica - pueda dar paso en su existencia a situaciones destructoras. Dicho de otra forma: en la conciencia del joven universitario se hace claro que ningún estamento puede encerrar de manera plena, total y exclusiva, la verdad.

Las consecuencias prácticas de estos postulados serán la acérrima lucha contra la figura del "gran Inquisidor", contra todo sistema de heteronomía cultural o religiosa que implique un autoritarismo cerrado, bien se presente con caracteres políticos o eclesiásticos. También aquí la experiencia personal juega un papel importante. Tillich recuerda dos acontecimientos que constituyen momentos decisivos en su postura crítica contra las instituciones y las doctrinas tradicionales de la lglesia, y que provocaron en él "una verdadera y creciente alienación práctica": el encuentro con las clases cultas y el encuentro con el mundo obrero.

"Mi encuentro con las clases cultas ocurrió bastante tarde, una vez terminada mi formación teológica y adoptada la forma peculiar de apologética, como correspondía a la situación de frontera" ${ }^{23}$. La apologética a que se refiere Tillich, seguida fielmente por él durante toda su vida, le lleva a buscar un punto común del cual pocler partir para un diálogo eficaz con las corrientes culturales modernas,

22. On the Boundary, p. 75 .

23. On the Boundary, p. 60. 
triunfantes desde la llustraciơn. En la búsqueda de esta base común descubre que tales corrientes "a pesar de su crítica al cristianismo y a la iglesia son esencialmente cristianas" 24

Después del duro trabajo y la sufrida lucha interior que le había costado el superar la identificación infantil entre autoridad y revelación, asi como el superar el sentimiento de culpabilidad que le producia en la infancia toda crítica a la autoridad paterna, Tillich levanta su protesta contra la llamada heteronomia bajo cualquier aspecto que presente. La heteronomía, "sujeción a autoridades divinas y terrenales, era precisamente lo que yo por mí mismo había logrado romper y a "lo que no quiero ni puedo volver" 25. La heteronomía, escribirá Tillich años más tarde recordando este periodo, es el afán de la religión por dominar la creatividad cultural autónoma desde fuera... El principio protestante, en cuanto derivado de la doctrina de la justificación por la fe, rechaza la heteronomía (representada por la doctrina de la infalibilidad papal) así como una auto-complaciente autonomía (representada por el humanismo secular). Exige, sin embargo, una autonomía auto-transcendente o una teonomía*'26.

Efectivamente, para Tillich el sistema más cercano a la heteronomía religiosa autoritaria es la Iglesia Católica, a la que él se opone de diversas formas: "Desde joven me enfrenté al sistema más característico de heteronomía religiosa, el catolicismo romano, con una protesta que era al mismo tiempo protestante y autónoma. La protesta no se refería ni se refiere, a pesar de las contraposiciones teológicas, a los contenidos dogmáticos o a formas de culto del sistema católico, sino que iba dirigida a su carácter heterónomo, a la áfirmación de una autoridad fundamental y normativa, aun cuando ni real ni intrínsecamente sea autoridad" 27 .

Pero así como la lucha contra la heteronomía católica se centra en el marco autoritario, la lucha contra la heteronomía protestante se centra en el marco de los principios teológicos, en la relación de lo infinito con la realidad humana de la religión. En este

24. On the Boundary, p. 61.

25. On the Boundary, p. 38.

26. The Protestant Era (Abridged Edition), Chicago 1957, p. xii. En adelante citaremos siempre esta edición. La primera de 1948 no se volvió a reimprimir completa.

27. On the Boundary, p. 39. 
caso se encuentran todas las ortodoxias protestantes de la historia: "el dogmatismo de las religiones, incluyendo la ortodoxia protestante y la última fase de la teología dialéctica, está fundada en el hecho de que una parte de la realidad humana-religiosa está revestida de lo absoluto-divino" ${ }^{28}$. Si a esta realidad humano-religiosa, bien sea un libro, una persona, una institución, o una doctrina, se le atribuye un carácter incondicional-divino, exigiendo a la vez, una sumisión completa, tenemos una situación demoníaca, en cuanto revestimos a lo finito-humano de una dignidad infinito-divina. La protesta tillichiana contra esta neo-ortodoxia no es una postura de autonomía humana liberal-secularista, sino que, en su visión, es una protesta profética, teónoma, crítica, que sigue la exigencia fundamental del primer mandamiento y que se expresa mediante el gran Principio Protestante.

La protesta tillichiana de los últimos años de universidad y de los primeros años de magisterio no se revela solamente contra la heteronomía católica y contra la neo-ortodoxia protestante sino también contra la teología liberal de sus maestros de Berlín, especialmente contra Hirsch y Harnack, tal como aparece en la Esencia del cristianismo $(1900)$ de éste último ${ }^{2}$. La finalidad de la crítica tillichiana a la teología liberal autónoma era el hacer ver que una razón meramente autónoma es incapaz de crear por sí misma "un mundo con contenido real", ya que termina por confundir a Dios con el mundo, y al hombre con su propio sentido. Tillich opta siempre por la teonomia, esto es, "por una autonomía informada de sustancia religiosa" ${ }^{30}$. Este es el gran intento de Tillich, nacido en la lucha por defender la transcendencia y la unicidad de Dios, y a la vez por defender la autonomía cultural. No es de extrañar que Leibrecht afirme: "La invitación de Paul Tillich a establecer una teonomía es su más grande desafío al pensamiento moderno". ${ }^{31}$.

28. On the Boundary, p. 40 .

29. Cfr. P. TrluICh, A History of Christian Thought, From Its Judaic and Hellenistic Origins to Existentialim, Edited by C. E. Braaten, New York 1972, p. 519. Esta obra fue publicada previamente en dos volúmenes separados: A History of Christian Thought y Perspectives on 19th and 20th Century Protestant Theoloqy, New York 1967-68.

30. On the Boundary, p. 38.

31. W. LEIBRECHT, en Religion and Culture. Essays in honour of $P$. Tillich, New York 1959, p. 17. 
Proletariado. EXPERIENCIA DE LA GUerRA,- Otro de los aspectos vitales que convulsionan la experiencia religiosa de Tillich es su encuentro con el mundo proletario. "El encuentro con el movimiento obrero, con las masas llamadas descristianizadas, me mostró claramente que también aqui se escondia una sustancia cristiana bajo la forma humanista" ${ }^{32}$. Educado dentro de la cultura y del ambiente eclesiástico-luterano tuvo que reaccionar ante el anquilosamiento y el conservadurismo de su Iglesia. Tal conservadurismo había producido ya sus consecuencias: el alejamiento de las clases trabajadoras y la pérdida de credibilidad para la misma Iglesia.

Tillich quiere encontrar las motivaciones más profundas de su participación en los problemas sociales de la Alemania postbélica recordando que ya su abuela habia construido barricadas en la revolución de 1848; pero sobre todo recuerda "la profunda impresión de las palabras de los profetas contra la injusticia y las palabras de Jesús contra el rico; todas estas palabras las aprendí de corazón en mi más tierna infancia" ${ }^{33}$.

La estructura eclesiástica luterana seguia unida a la clase socialmente alta, a la llamada burguesía Durante los primeros años de escuela en Schönfliess, Tillich vio de cerca "la animosidad de los compañeros contra la clase social superior representada por mis propios padres, junto con las familias del alcalde, médico, farmacéutico, algunos comerciantes y pocos más... El hecho de pertenecer a esta clase privilegiada me produjo en esta temprana época la conciencia de culpabilidad que más tarde había de ser tan decisiva para mis trabajos y destino en la vida" ${ }^{34}$. Sus mismos padres se sentían ligados socialmente a los grandes terratenientes de la feligresia, y la infancia y juventud de Tillich siguió estos cauces burocráticos de la burguesía de principios de siglo: clases particulares de latín con los hijos de los ricos, la ida al Gymnasium de Könisberg y los estudios universitarios.

Fue la guerra la que marcó un hito en su vida y en su trabajo. Fue el último y definitivo acontecimiento que le liberó por completo de los lazos idealistas, burgueses y aristocráticos que le quedaban, abriéndole a la escena política y social, y haciéndole consciente de

32. On the Boundary, p. 62.

33. The Theology of P. Tillich, p. 12.

34. On the Boundary, p. 19-20. 
los innumerables privilegios académicos de la anteguerra. El mismo Tillich nos ofrece un testimonio de esta transformación: "La transformación me vino durante la batalla de la Champagne de 1915. Hubo un asalto nocturno. Durante toda la noche no dejé de rondar en torno a los heridos y moribundos; algunos de ellos eran íntimos amigos míos. Durante aquella terrible noche caminé entre filas de gente que moria. En aquella noche, gran parte de mi filosofia clásica se hizo pedazos: la convicción de que el hombre fuera capaż de empadronarse de la esencia de su ser, la doctrina de la identidad de la esencia y la existencia... Recuerdo que me senté bajo los árboles del bosque y leía Asi habló Zaratustra de Nietzsche, como hacían otros muchos soldados alemanes, en continuo estado de exaltación. Esta era la liberación definitiva de la heteronomia" ${ }^{35}$. Recordando esta misma batalla, Tillich solia decir a su amigo Rollo May: "Aquella noche me transformó. Aquella noche me convertí en existencialista" ${ }^{36}$. El idealismo estudiado en las facultades de filosofía no solucionaba los problemas de aquellos hombres que sufrían, temblaban de miedo y querian seguir viviendo. La realidad no solamente es la manifestación de la pura esencia, sino también su misma contradicción. La realidad de la existencia humana, en su análisis concreto, manifiesta abiertamente la contradicción con la esencia. Esta tesis del segundo pexíodo Schelling se hizo vida en Tillich, en aquellos días tristes de la guerra. El pensamiento burgués, comodón, seguro de sí mismo, que queria olvidarse del elemento trágico de la vida y de la historia, no tenía cabida en aquellos días de desastre y de sangre.

El absurdo de las destrucciones, la soledad del individuo ante tanta catástrofe, la impotencia de un capellán por remediar esos males y el convencimiento de que las clases industriales consideraban a la Iglesia como "aliada incuestionable", forman parte de esa experiencia transformadora. Juntamente con la caida del idealismo, de la burguesía y del predominio del cápitalismo, también se vieron sometidas a la crítica y a la duda la fe de las Iglesias, sus viejas tradiciones y convencionalismos, asi como la fe en el progreso. La historia presentaba, en su más dura realidad, el elemento demoníaco que lleva dentro de sí:

35. En el Time del 6 de marzo de 1959 , p. 47 ; citado por B. Mondrn, $I$ grandi teologi del secolo $X X$, Torino 1969 , t. II, p. $87-88$.

36. R. MAY, Paulus. A personal Portrait, p. 18. 
Le sobrevino el convencimiento de que aquella clase obrera había sido hasta el presente objeto de explotación por parte de estructuras y estamentos en los que él mismo había participado hasta el presente: el Estado, la Iglesia, la burguesía feudal y el ejército. El cambio se imponía para ser fiel a la Iglesia a la que pertenecía y al mundo a quien debía servir. En una palabra; había comprendido que su labor de pensador y de eclesiástico no podía reducirse a ofrecer soluciones generales y abstractas, sino que debería concretarse a la realidad del momento, aun con el riesgo del error. El compromiso con la historia estaba hecho. Se acercaba un cambio social, que él interpretó en sentido cristiano, como un cambio hacia un socialismo religioso. No es que esperara la utopia del cumplimiento total del Reino de Díos, de carácter escatológico y transhistórico, sino que comprendió que "el Reino de Dios puede aparecer también como un juicio contra una determinada forma de sociedad y como una norma para una nueva sociedad. De este modo, la decisión de ser un socialista réligioso puede ser una decisión por el Reino de Dios; aunque la sociedad socialista esté infinitamente distante del Reino de Dios" $"$ ?

Formación universitaria.- "Yo jamás dudé - ni lo dúdó nadiede que estaba llamado a una vida dedicada a lo intelectual más que a las materias prácticas. Tendría yo unos ocho años cuando por vez primera me sentí conmovido por la idea del Infinito. Tanto en la escuela como en la instrucción para la Confirmación quedé entusiasmado por la dogmática cristiana" ${ }^{38}$. Pero comprendió pronto que la verdad religiosa lleva consigo el mundo de la praxis. "La verdad religiosa se hace, conforme al evangelio de San Juan.". Los últimos años de Gymnasium (1900-1904) dieron a Tillich la posibilidad de llegar a un perfecto dominio del latín y del griego, leyendo ya a esa edad algunos filósofos clásicos. El mismo confiesa que "en este tiempo aprovechaba toda hora libre para leer libros de filosofia que por azar caian en mis mano's" "39. Fue así como leyó la Historia de la filosofia de Schwegler encontrada en una vieja vicaria rural; la Doctrina de la ciencia de Fichte, comprada de ocasión en una calle de Berlín; la Crítica de la razón pura de Kant, movido de emoción al

37. On the Boundary, p. 79 .

38. On the Boundary, p. 30.

39. On the Boundary, p. 46; The Theology of $P$. Tillich, pp. $9-10$. 
poderla adquirir por un marco en una librería. "En estos años, sin haber comenzado la universidad, Tillich mantiene frecuentes diálogos sobre la libertad y la necesidad; Dios yel mundo; el idealismo y el realismo.

En 1904, a la edad de 18 años, comienza sus estudios universitarios. "Cuando entré en la universidad, yo tenia ya un buen conocimiento de la historia de la filosofía y una fuerte base sobre Kant y Fichte. Siguieron Schleiermacher, Hegel y Schelling" "40. Tuvo la suerte de frecuentar las mejores universidades de la época: Berlín Halle y Tübingen "En la Alemania de entonces se alimentaba la idea de que tanto la teología como la filosofía no tenían representantes más dignos que la universidad alemana: "teníamos el convencimiento de que sólo en Alemania se tomaba completamente en serio el problema de la unión entre el cristianismo y el espíritu moderno" " ${ }^{2}$. En el fondo triunfaba todavía el liberalismo teológico y el humanismo filosófico, una especie conjunta de filosofía de la religión (la Weltauschaung) que intentaba hacer la gran sintesis, llegando a identificar de manera esencialista el espíritu pensante y la realidad, ignorando la existencia de lo trágico y lo ambiguo de la historia y de la vida de los hombres. Dos puntos merecen la pena destacarse: la influencia de Schelling $(+1854)$ en filosofía y la influencia de su maestro Martín Kähler en teología.

a) Estudioso de Schelling.- Tillich recuerda como su maestro principal en filosofía al profesor Fritz Medicus, especialista en Fichte, sobre el que había publicado varias obras contribuyendo eficazmente a revitalizar el pensamiento de Fichte y a generalizar el pensamiento idealista en el primer decenio del S. XX. Pero Tillich se centra por encima de todo en F. Wilheim Schelling, dado el atrac-

40. The Theology of $P$. Tillich, p. 10.

41. El 'curriculum' universitario de Tillich lo encontramos descrito a la perfección en una carta a Thomas Mann, mayo de 1943: "I myself registered in the theological program in Berlin in the fall of 1904. In the spring of $1905 \mathrm{I}$ went to Tübingen and in the fall of 1905 to Halle where I studied for four semesters. In the fall of 1907 I returned to Berlin and took my first theological examination before the consistory of Brandeburg in the winter of 1909, and my second theological examination before the same body in 1912. I was ordained by the General Superintendent of Brandeburg in August of 1912. In the meantime I had taken my $\mathrm{Ph}$. D. in Breslau in 1910 and my Licentiate of Theology in Halle in 1911" "Paul Tillich's Letter of May 1943 to Thomas Mann", en The intellectual Legacy of Paul Tillich, Detroit 1969, p. 102)

42. Theology of Culture, p. 161 . 
tivo que su doctrina tenía para el joven alumno universiario. "En los años de universidad leí entusiasmado varias veces sus obras completas y sobre él hice mi tesis doctoral en filosofía y mi memoria de licenciatura en teología" ${ }^{43}$.

La impostación de la problemática filosófico-teológica de Schelling cautiva a Tillich. El problema fundamental de Schelling es la relación de lo Infinito con lo finito, de Dios con el hombre y el mundo. La tesis doctoral de Breslau (1910) es una exposición de los presupuestos y de los contenidos de la religión de Schelling en torno a este problema. Si la conciencia humana es la única fuerza creada que puede saber algo de Dios, la consecuencia lógica es que la historia de la humanidad es, en el fondo, una historia religiosa; y el proceso cultural humano hunde sus raíces en lo religioso, bien sea de manera consciente o inconscientemente. A Dios habrá que encontrarle en la historia ${ }^{44}$.

Proyectando la perspectiva general le Schelling a la relación concreta Dios-hombre, Tillich encuentra una doble polaridad para expresar la experiencia religiosa de Schelling: la experiencia mís tica y la experiencia del sentimiento de culpabilidad, tal como aparece en el mismo título de la memoria presentada en Halle (1911). La mística, como experiencia de identidad con el Absoluto; y la culpabiliad, como experiencia existencial de la alienación, separación y conflicto entre el Dios siempre Santo y el hombre pecador, son los temas que estarán siempre presentes en las disertaciones posteriores de Tillich. Tanto el idealismo en general, como Schelling en particular, dejaron huellas profundas en el alma del joven universitario. Del idealismo mantendrá siempre la idea de la correspondencia entre el espíritu humano y la realidad, aunque rechaze la postura orgulloso-idealista de que el pensar condiciona y dirige toda la realidad. La experiencia de la guerra, a la que hemos aludido, le liberó de ese fantasma burgués haciéndole ver la realidad concreta de la existencia humana ${ }^{45}$.

43. On the Boundary, p. 47. La tesis de Filosofía lleva por titulo: Die religionsgeschichtliche Konstruktion in Schellings positiver Philosophie, ihre Voraussetzungen und Prinzipien (Universidad de Breslau, 1910). La memoria de Teologia fue sobre: Mystik und Schuldbewusstsein in ScheIlings philosoxhischer Entwicklung (Universidad de Halle, 1911).

44. La importancia del pensamiento de Schelling en Tillich ha sido estudiado por D. O'Hanlon, The influence of Schelling in the thought of Paul Tillich, Univ. Gregoriana, Roma 1958.

45. Cfr. R. May, Paulus. A Personal Portrait, p. 18. 
b) Admirador de Martín Kähler. Los estudios teológicos en Halle (1905-1907) significan un paso importante en la evolución de Tillich. De Halle recordará siempre a su maestro Martín Kähler. "Kähler era un hombre arrollador por su habilidad intelectual y por su fuerza moral y religiosa. Como maestro y escritor era difícil de entender. En muchos aspectos era el más profundo y el representante más moderno de la teología de la mediación del s. XIX. Era adversario de Albrecht Rischl, defensor de la doctrina teológica de la justificación y crítico del idealismo y del humanismo, de donde él mismo procedía" ${ }^{46}$.

De Kähler aprendió Tillich la doctrina paulino-luterana de la justificación mediante la fe que "niega toda exigencia humana ante Dios y cualquier identificación de Dios con el hombre" "27. La interpretación de Kähler ofreció a Tillich la posibilidad de dar un paso importante en su existencia luterana, dado "que el principio de la justificación mediante la fe se refiere no sólo a la vida religioso-ética sino también a la vida religioso-intelectual. La situación de duda, aun de duda acerca de Dios, no nos separa necesariamente de Dios. Existe fe en toda duda seria, es decir, la fe en la verdad como tal, aun cuando la verdad que podemos expresar es solamente nuestra carencia de verdad. Si esa situación es experimentada en su profundidad y como preocupación última, entonces lo divino está presente; y el que duda en tal actitud es "justificado" en su pensamiento" 48 :

Por otra parte, Tillich apreciaba la enorme labor cientifica llevada a cabo por la escuela crítica-radical de carácter histórico. Su gran problema era el poder reconciliar la doctrina de la justificación, tal como venía expuesta por su maestro, con los descubrimientos científicos de la crítica histórica. Tillich aceptó en parte el método crítico-histórico respecto a los libros del Antiguo y Nuevo Testamento, aunque rechazó siempre el naturalismo teológico y el moralismo de Wellhausen y de Gunkel. Todo esto provocó en él una fuerte crisis como recordará al final de su vida (1963): "Yo mismo experimenté una fuerte crisis en mi desarrollo cuando dejé Halle (1907) en donde se afirmaba tajantemente este nuevo bibli-

46. On the Boundary, p. 47-48.

47. On the Boundary, p. 48.

48. The Protestant Era, p. xi. 
cismo, y comencé a estudiar por mi cuenta la historia de la critica

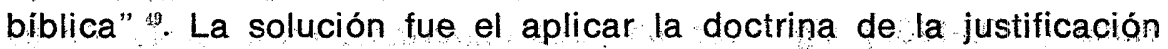
a la esfera del conocimiento humano. No solamente las acciones del hombre sino también su pensamiento caen bajo el juicio de Dios. Lo importante es tener una preocupación última, y tal preocupación última siempre tiene un carácter religioso: "La justificación del que duda corresponde a la justificación del que peca". La gracia llega a todos. "Tú no puedes alcanzar a Dios por el trabajo de un recto pensamiento o por el sacrificio de la inteligencia o por una sumisión a autoridades externas, tales como la doctrina de la Iglesia o de la Biblia. Tú no puedes, y ni debes intentarlo. Ni las obras de piedad, ni las obras de moralidad, ni las obras del entendimiento establecen la unión con Dios. Tớas ellas son consecuencias de esta unión, pero ellas no la consiguen... Pero así como tú eres justificado como pecador (aunque injusto, tú eres justo), así en el estado de duda tú estás en estado de verdad... Esta seriedad incondicional es la expresión de la presencia de lo divino en la experiencia de una total separación de ello. Esta interpretación radical y universal de la doctrina de la justificación por la gracia mediante la fe fue la que hizo de mi un Protestante consciente" "50.

Las consecuencias de este Principio Protestante son de suma importancia para el futuro teológico de Tillich, ya que fundamentan, en parte, su concepción futura de la Iglesia latente y la posible presencia del Espíritu fuera del marco de las Iglesias institucionalizadas. No hay posible estadio de la cultura y de la vida que no tenga, de una u otra forma, una relación al Incondicional. Esta es la verdadera teología de la mediación tillichiana, la verdadera teologia dialéctica, "que media entre el criterio de la verdad tal como aparece en la figura de Jesús como el Cristo y las experiencias siempre cambiantes de los individuos y de los grupos" si.

49. A History of Christian Thought, p. 521.

50. The Protestant Era, p. xi.

51. The Protestant Era, p. IX. 


\section{I1: LA VIDA EN PLENITUD (1919-1965)}

Después de la guerra, y tras un breve paréntesis de actividad parroquial, comienza el profesorado universitario de Tillich. Fueron 46 años ininterrumpidos de magisterio, de los cuales 14 en Alemania (1919-1933) y 32 en los Estados Unidos de América (1933-1965). Sin duda alguna, el primero de estos periodos es el más rico de contenido y el más denso de toda la vida de nuestro autor. $Y$ esto no sólo por el compromiso social y político de carácter profético que ejerció en la Alemania pre-nazi, sino fundamentalmente por la maduración de toda su doctrina; por la creación de un nuevo lenguaje teológico que pudiera traducir a nuestra mentalidad moderna el mensaje siempre eterno del evangelio, por el encuentro vivo con el mundo del arte, de la filosofía existencialista, del marxismo, de la educación y de la historia.

Los cinco años de Berlín (1919-1924) los pasó como Privatdozent de teologia en la universidad, incluyendo en sus explicaciones todo aquello que encierra el título "Teología de la Cultura": la relación de la religión a la politica, al arte, a la filosofía, a la psicología profunda y a la sociología. Contra su voluntad hubo de aceptar la cátedra de teología de Marburg, en donde permaneció tres semestres (1924-1925), palpando de cerca la enorme influencia que alli ejercia ya la teología neo-ortodoxa de Barth y la indiferencia hacia el mundo de lo político y de lo social por parte de los profesores y alumnos. Este contraste fue el que le movió a sistemar su propio pensamiento teológico, comenzando aquí la Systematic Theology, cuyos tres volúmenes aparecerian decenios más tarde (1951-19571963). La estancia en Marburg le ofreció también la ocasión de conocer y tratar a Heidegger, profesor de filosofia en la misma universidad. El existencialismo de Heidegger, en cuanto contempla y descubre los elementos oscuros de la existencia humana, fue un aliado de Tillich en la elaboración de su teología. "Pasarón años antes de que me diera perfecta cuenta del impacto de este encuentro sobre mi propio pensamiento. Resistí, intenté aprender, y acepté este nuevo modo de pensar más que las respuestas que ofrecia" ${ }^{52}$.

52. The Theology of Paul Tillich, p. 14. 
Las discusiones levantadas en torno ai existencialismo tillichiano vienen esclarecidas por él mismo. Preguntado en ocasiones si era existencialista, solía repetir que mitad-mitad (fifty-fifty). Admitía el método heideggeriano para el análisis fenomenológico de la existencia, pero jamás las soluciones que ofrecía. El ejemplo que pone sobre la importancia del existencialismo, en cuanto instrumento de trabajo, es claro: así como el análisis marxista de las estructuras de la sociedad ha contribuido a despertar en las Iglesias una responsabilidad mayor hacia las condiciones sociales de los hombres, así también el existencialismo ha contribuido a hacer consciente a la teología de la necesidad que tiene de contemplar al hombre en su existencia concreta, en el tiempo y en el espacio. Podríamos decir que Tillich defiende y usa un esencialismo existencial ${ }^{53}$

Después del paso por las universidades de Dresden y Leipzig (1925-1929), que le ofrecieron la oportunidad de seguir en contacto con el mundo de la cultura llamada profana, especialmente con el mundo del arte, acepia en 1929 la cátedra de filosofía de la universidad de Frankfurt (1929-1933). En Frankfurt, "la universidad más moderna y más liberal de Alemania", explica filosofía existencial ampliando su acción con innumerables conferencias y artículos, dando lugar de esta forma a los primeros conflictos serios con el movimiento nazi. El 31 de enero de 1933 Hitler es llamado a la Cancillería del Reich. El Nacional-Socialismo habia conseguido el $44 \%$ de los votos en las elecciones. Con la ayuda del Partido Nacional Alemán, Hitler consigue la mayoría parlamentaria. Días más tarde, el 6 de febrero de 1933, Paul Tillich es expulsado de la universidad, siendo el primer profesor cristiano que sufria tal vejación. A requirimiento de su amigo Reinhold Niebuhr y de Horace Friess, jefe del Departamento de Filosofía de la universidad de Columbia, Tillich marcha a América con su familia, llegando a New. York el 4 de noviembre de ese mismo año. Contaba cuarenta y siete años de edad.

53. "Existentialim is possible only as an element in a larger whole; as an element in a vision of the structure of being in its created goodness, as then as a description of man's existence within that framework. The conflicts between his essential goodness and his existential estrargement cannot be seen at all without keeping essentialism and existentialism together. Theology must see both sides, man's essential nature, wonderfully and symbolically expressed in the paradise story, and man's existential condition, under sin, guilt, and death" ( $A$ History of Christian Thought, p. 541). 
Permaneció en el Union Theological Seminary durante 22 años (1933-1955) como profesor de teología. Después de su jubilación fue llamado por la Harvard con el más alto título de esa benemérita institución: Harvard's University Professor (1955-1962). A partir de 1962 pasa a la universidad de Chicago, en donde muere el 22 de octubre de 1965.

Soctalismo Religioso.- De todos es conocida la situación del pueblo alemán al terminar la primera guerra mundial. La nación estaba en un caos total: económico-político-social y religioso. Con la guerra había terminado el período de la burguesía del s. XIX, dando lugar al nacimienio de unas clases sociales bien marcadas: el proletariado alejado desde decenios de las Iglesias, y las Iglesias luteranas aliadas de una manera o de otra con las clases dirigentes. La revolución socialista de noviembre de 1918 provoca la renuncia del Emperador Guillermo II al trono. Dos ideas de tipo político hacen acto de presencia: el principio democrático de las naciones de Occidente y el sentimiento nacionalista que se acentúa aún más a raíz de las imposiciones de los vencedores en la paz de junio de 1919. La instauración de la República de Weimer en agosto de 1919 no consigue la estabilidad deseada, dando lugar a una grave crisis espiritual y una considerable decadencia moral. A escala eclesial, las Iglesias luteranas perdieron el apoyo de los príncipes y la dependencia que tenían del Estado, mitigándose el dominio estatal en las cuestiones eclesiásticas ${ }^{54}$.

Tillich considera el "Socialismo Religioso alemán" de la postguerra como una continuación o una herencia del pensamiento religioso-social de los Blumhardt, especialmente de Christoph Blumhardt (†1919), quien aplicó las ideas de su padre sobre "el Dios que salva" a las realidades sociales. La idea central era que Dios amaba al mundo y no solamente a la Iglesia y a los cristianos, "oponiéndose al tipo individualista de religión que caracteriza al luteranismo pietista de ese tiempo" 55. El Reino de Dios debe aparecer también como intrahistórico, sin descuidar la transcendencia. Era una

54. The Protestant Era, p. xiii; R. MaY, Paulus. A personal Portrait, p. 8.

55. A History of Christian Thought, p. 530-531; Cfr. La fede dei socialisti religiosi. Antologia di testi a cura di W. DEREsch, Milano 1974, pp. 30-31. 
especie de autocrítica profética, nacida en el interior de las Iglesias. $Y$ si éstas no son capaces de aceptarlas; los mismos movimientos seculares levantarán la voz en contra de ellas mismas.

Junto con su amigos de Berlín, Tillich emprende la lucha, nada más terminar la guerra, en un doble campo. El problema que se trata de resolver es el siguiente:

\begin{abstract}
"¿Cómo superar el abismo existente entre el transcendentalismo luterano y el utopismo secular de los grupos socialistas? La idea luterana afirmaba que el mundo es algo que está en manos del demonio y que el único poder es la autoridad del Estado. Por tanto, los movimientos revolucionarios deben ser negados y la idea de transformar la sociedad en nombre de Dios no recibió respuesta alguna dentro de la tradición oficial luterana. La idea secular era que la revolución estaba a la vuelta de la esquina. Su llegada era una cuestión de cálculo científico... Esta idea secular no encierra nada de transcendente; sino que cree que con la llegada del socialismo serán solucionados todos los problemas humanos" ${ }^{56}$.
\end{abstract}

La lucha se centra, pues, contra el transcendentalismo luterano y contra el utopismo secularista de los movimientos sociales laicos. Dentro del campo luterano existen, según Tillich, dos movimientos que se oponen al Socialismo Reígioso: el nacionalismo religioso de Emmanuel Hirsch, enemigo político y teológico de Tillich, y la neoortodoxia de Karl Barth. El Socialismo Religioso fue incapaz de superar las barreras de la indiferencia barthiana en estos años hacia los problemas sociales y políticos, así como fue incapaz también de superar el fanatismo religioso-nacionalista de Hirsch, tan ligado a las tradiciones religiosas, sociales y políticas de la nación alemana ${ }^{57}$.

La tarea principal de Tillich y su grupo de Berlin era la de ofrecer una interpretación cristiana del hombre y una interpretación cristiana de la historia. De este modo creían poder hacer de puente entre las masas descristianizadas enroladas en los movimientos socialistas seculares y el pietismo de las Iglesias oficiales. La respuesta a estas interpretaciones viene dada en el análisis de tres conceptos fundamentales: daimon-kairos-teonomia.

56. A History of Christian Thought p. 533 .

57. Cfr. On the Boundary, p. 76 . Ver nota 66 de este mismo trabajo 
a) Daimon. "La idea de lo demoníaco es la expresión mítica de una realidad que ocupaba el centro de la experiencia tanto de Lutero como de Pablo, es decir. el poder estructural è inevitable del mal" ${ }^{58}$. El psicoanálisis freudiano y el análisis marxista de la historia han demostrado claramente la presencia de estructuras demoníacas en el individuo y en los grupos; estructuras de destrucción que a veces prevalecen sobre el poder creativo y progresista de la historia y del individuo. La presencia del pecado, de la culpa, de la voluntad de poder... hacen imposible toda utopía antropológica. El Reino de la justicia y de la paz jamás se rea'izará plenamente en este mundo ${ }^{5:}$. El liberalismo teológico, de carácter humanista-religioso, pretende ignorar esta realidad. El Socialismo Religiosó trató de demostrar que tanto el capia'ismo como el Nacional-Socialismo son estructuras demoníacas, ya que divinizan sus más altos valores. Si por encima de nuestra libertad limitada y de nuestra buena voluntad existe esta estructura "demoníaca" en el hombre y en la historia, el cristianismo debe predicar que solamente la gracia es capaz de superar esta situación. Y la gracia es siempre un don de Dios, presente en la historia ${ }^{60}$.

b) Kairos. Cuando el poder demoníaco es reconocido en un momento dado de la historia y se lucha en contra de él, en este momento tiene lugar la irrupción de lo eterno en el tiempo. Este momento, "llamado "momento oportuno", un tiempo cualitativo, es un kairos. "Kairos, la 'plenitud del tiempo', según el uso que hace el Nuevo Testamento de esta palabra; describe el momento en el cual lo eterno irrumpe en el tiempo y lo temporal se prepara para acogerlo. Lo que aconteció en el principal KAIROS, la aparición de Jesús el Cristo, como centro de la historia, puede suceder nuevamente de una forma derivada en el devenir del tiempo". ${ }^{61}$.

58. The Protestant Era, p. xvi.

59. Cfr. On the Boundary, pp. 78-79

60. Tillich ha expuesto su pensamiento sobre el concepto de daimon en los siguientes trabajos: "Grundlinien des religiösen Sozialismus", en Blätter für religiösen Sozialismus, 4 (1923), n. 8-10, pp. 1-24 (también en Gesammelte Werke XIV, pp. 91-119); "Religionsphilosophie", en Léhrbuch der Philosothie, vol. II, Berlín 1925, pp. 765-835 (GW I, pp 297-364); Das Domonische. Ein Beitrag zur Sinndeutung der Geschichte, Tübingen 1926, (GW VI, pp. 42-71); "Der Begriff des Dämonischen und seine Bedeutung. für die Systematische Theologie", en Theologische Blätter, 5 (1926), pp. 32-35 (GW VIII, pp. 285-291).

61. The Protestant Era, p. xv. 
El término kairos fue uno de los conreptos principales acuñados por el Socialismo Religioso, y no pretende indicar que la llegada de un nuevo orden implica la realización plena del Reino de Dios, sino que "en un determinado tiempo se plantean determinados problemas, y se nos manifiesta un determinado aspecto del Reino de Dios como exigencia y como espera" 62. El Reino de Dios juzga el momento concreto de la historia, invitando al creyente a su interpretación y a la acción. De ahí que kairós fuera el concepto fronterizo entre un socialismo secular utopista y un transcendentalismo pietista. Decidirse por el Socialismo Religioso era para Tillich decidirse por el Reino de Dios. En contra del utopismo secularista, el Socialismo: Religioso reconoce y afirma la posibilidad de logros fragmentarios en la historia, la posibilidad de que una determinada estructura demoníaca pueda ser superada; pero a la vez afirma también que - dentro del espacio de la historia- jamás se conseguirá un triunfo definitivo sobre lo "demoniaco" 63.

c) Teonomia.- Este tercer concepto había sido ya asimilado por Tillich en la reinterpretación del Principio Protestante de la justificación mediante la fe. Aplicado al Socialismo Religioso, Tillich dice que éste "debe ser entendido como cierta tendencia hacia una nueva teonomía. Es más que un orden económico. Es un entendimiento comprehensivo de la existencia, es la forma de autonomía exigida y esperada por el kairos actual". 64. La teonomía que predica el Socialismo Religioso supera, pues, la autonomía secularista que carece de todo pensamiento crítico; y supera igualmente la heteronomía que implica esclavitud. Se trata de que los valores eternos irrumpan en el nuevo orden social. Desde el punto de vista cristiano, se trata de hacer presente en la historia el principio que le ofrezca un sentido, y que no es otro que Jesús el Cristo, centro y sentido de la misma historia. "La teonomía es la unión de aquello que es

62. On the Boundary, p. 79.

63. Los principales estudios que tienen por tema el kairos son los siguientes: "Kairos", en Die Tat, 14 (1922), pp. 330-350 (GW VI, pp. 9-28); "Kairos. Ideen zur Geisteslage der Gegenwart", en Kairos, Darmstadt 1926 (GW VI, pp. 29-41); "Kairos und Logos", en Kairos, Darmstadt 1926 (GW IV, pp. 43-76); "Between Utopianism and Escape from History", en Colgate-Rochester Divinity School Bulletin, 31" (1959), pp. 32-40 (GW VI, pp. 149-156). Posteriormente Tillich ha resumido su pensamiento sobre este tema en la Systematic Theology III, pp. 369-372.

64. On the Boundary, p. 82. 
verdad en la autoriomía y en la heteronomía; la realización de una sociedad con substancia espiritual, a pesar de la libertad del desarrollo autónomo y a pesar de vivir dentro de las grandes tradiciones en las que el Espíritu se ha encarnado" ${ }^{65}$.

La complicada historia del Socialismo Religioso viene a ser la historia de sí misma. Fueron muchos los grupos nacidos con el mismo afán, a raíz del fin de la guerra. Cada grupo tenía su propia peculiaridad. El grupo formado en Berlín (1919) en torno a Paul Tillich, Mennicke y Heimann, llevó a cabo una labor eminentemente cultural, en sentido religioso y teológico, cuya finalidad era, como hemos visto, superar el abismo entre socialismo y cristianismo. Su acción se difundió en los medios intelectuales mediante la publicación de varias revistas: Blätter für religiöse Sozialismus (1920-1927) bajo la dirección de Mennicke, y Neue Blätter für den Sozialismus (1930-1933) bajo la dirección de Tillich en Frankfurt. A través de estas revistas, así como en sus conferencias, manifestaron su clara oposición al capitalismo reinante y al nacionalismo exaltado, causas de la guerra pasada. Igualmente tuvieron que luchar contra las Iglesias oficiales que les consideraban como herejes, así como contra los teólogos barthianos. Es en este tiempo cuando tiene lugar la primera confrontación literaria entre Tillich y Barth ${ }^{66}$.

65. A History of Christian Thought, p. 534. Sobre el concepto de teonomía cfr.: "Theonomie", en Die Religion in Geschichte und Gegenwart 2. ${ }^{a}$ ed. Tübingen 1931, vol. V, pp. 1128-1129; Das System der Wissenschaften nach Gegentänden und Methoden, Göttingen 1923 (GW I. pp. 111-293, principalmente en las páginas 271-283); Religiöse Verwirklung, Berlin 1930,312 x.; "Author's Introduction" a The Protestant Era, pp. xi-xii"; Systematic Theology (ST). III, pp. 249-268.

66. Ante la segunda edición de la Römerbrief Tillich publica un artículo: "Kritisches und positives Paradox. Eine Auseinandersertzung mit $K$. Barth und F. Gogarten", en Theologische Blätter, 2 (1923), pp. 263-269; y un segundo artículo de contrarrespuesta a Barth: Antwort, A través de ambos artículos, después de alabar a Barth por su entereza en recobrar para Dios el puesto debido, sintiéndose en este punto solidario con él, expone claramente el peligro serio de supernaturalismo que acecha a Barth; a la vez que aboga una vez más por una verdadera teonomia. Ambos trabajos se encuentran recogidos en Gesammelte Werke (GW) VII, pp. 216225 y pp. $240-243$.

Las relaciones entre Barth y Tillich es un capitulo interesante de la historia de la teologia de este periodo. No solamente por los diferentes matices de impostación teológica, sino principalmente por los compromisos diversos que ambos tomaron respecto a los mismos acontecimientos históricos: mundo del proletariado, clases sociales, Nacional-Socialismo, asi como la terribe persecución del primero de abril de 1933 contra los judíos. Barth, encerrado en su transcendencia teologica, Ignoró o no supo intuir durante años el peligro del nazismo. De hecho, la primera reacción de 
Mal vistos por sus mismas Iglesias y en nada ayudados por la Social Democracia (SPD), el grupo de Tillich siguió combatiendo en Frankfurt por los grandes principios ético-religiosos: superación del individualismo pietista a favor de una Iglesia responsable.socialmente, especialmente inclinada hacia los oprimidos; condena del capitalismo egoísta y del comunismo ateo; denuncia del nacionalismo alemán y lucha abierta en los últimos años contra el NacionalSocialismo. Esto último le procuraría la expulsión de la universidad.

LA EMIGRACIón.- Tillich pasó en Frankfurt los últimos cuatro años de su estancia en Alemania (1929-1933), ocupando la cátedra de filosofía que había quedado vacante por la muerte prematura de Max Scheller. Durante esos años intuyó el peligro inminente del nuevo movimiento nacionalista dirigido por. Hitler. No dudó en mo-mento alguno de calificarlo como "demoníaco", como una estructura diabólica que eleva a divinidad valores finitos, como "paganismo nacionalista" ${ }^{67}$. Aunque personalmente jamás se enroló en partido alguno político, su acción cultural tuvo gran repercusión política. En este contexto de denuncia profética aparece el cuarto número de Neue Blätter für Sozialismus (1931) dedicado plenamente al examen del Nacional-Socialismo. Tillich colabora con un artícufo: Das Problem der Macht en que analiza el sentido de la autoridad, confutando las tesis nacionalistas. De más compromiso político es: Protestantismus und politische Romantik (1932) en contra del apoyo de las Iglesias oficiales al movimiento nacionalista de Hitler, anunciando que la nueva ideología, basada en el mito del origen, conduciría a Alemania al caos y a la autodestrucción ${ }^{68}$. $\mathrm{Fi}$ -

Barth contra el Nacional-Socialismo data de julio de 1933, Hasta entonces no habia comprendido que el movimiento dirigido por Hitler era un movimiento cuasi-religioso que representaba un ataque directo contra la humanidad y contra las mismas iglesias. (Cfr. A. History of Christian Thought, p. 539). La obra de F.W. MARquard, Teologia e socialismo. L'esempio di Karl Barth, Milano 1974, deja al descubierto este período y no desautoriza las afirmaciones de Tillich.

67. On the Boundary, p. 26.

68. "Der Protestantismus durchschaut nicht mehr, dass das Bündnis, das ihm besonders die revolutionäre Form der politischen Romantik anbietet, nich auf dem Willen beruht, sich der prophetischen Kritik des protestantischen Prinzips zu unterstellen, sondern auf dem Willem, den Protestantismus in den Dienst einer absolut gesetzten politischen Idee zu stellen, sich die priesterliche Weihe für den neuen Mythos geben zu lassen Die lage ist deswegen so schwierig, weil die evangelischen Kirchen in den 
nalmente, y en plena crisis, aparece su libro Die sozialistische Entscheidung ${ }^{6}$, en donde de manera provocadora anatematiza, en nombre del Principio Protestante, la heteronomía romántica del Nacional Socialismo y el mito del origen; advirtiendo a las Iglesias que perderían su esencia profética y su raíz protestante en caso de seguir ayudando y entregándose en manos del nuevo régimen que se avecinaba.

Su fidelidad al evangelio y su fidelidad a los hombres le llevaron a realizar toda una serie de signos proféticos y acciones comprometidas. Rollo May nos narra algunos detalles oidos personalmente a Tillich: "Uno de sus estudiantes fue golpeado fuera de la clase por los encapuchados nazis. El mismo Tillich ayudó a meterlo dentro del edificio. En sus clases arremetía frecuentemente contra los nazis con las palabras más fuertes de su vocabulario. El y su esposa Hannah fueron en cierta ocasión a escuchar a Hitler, logrando ocupar un puesto en la misma plataforma del orador. Después del mitin, ambos estaban desesperados; éste es un bárbaro que no debería usar la lengua alemana, se lamentó Tillich" "

El doblegarse de las Iglesias oficiales alemanas, la quema de libros y el miedo continuo a ser descubierto por sus escritos clandestinos hicieron que Tillich se enfureciera ante esta conducta maniática. No obstante esto, y a pesar de verse expulsado de la universidad de Frankfurt y comprometida su misma vida, él se oponía a salir de su patria. De hecho acudió a conversar con el Secretario de Educación, al cual propuso dos cuestiones: si iba a continuar la persecución contra los judíos y cómo se iba a comportar la policía con la nueva cultura. El mismo Secretario le instó a que abandonara la patria, al menos por dos años. Esto, juntamente con las advertencias de sus amigos sobre el peligro qu corría su vida, le forzó a aceptar la invitación de R. Niebuhr y H. Friess para trasladarse a

letzten Jahrzehnten immer ausschliesselicher von denjenigen Gruppen getragen wuräen, die zugleich träger der politischen Romantik sind, während ơie übrigen Gruppen, Bürgertum, Proletariat, weiteste Krøise des Beamtentums, sich von dem Leben der protestantischen Kirche immer mehr entfernt haben. Unter diesen Umständen ist kaum abzusehen, wie der deutsche Protestantismus dem Schicksal entrinnen soll, in die Katastrophe der politischen Romantik und seiner Ideologie hineingerissen $\mathrm{zu}$ werden" (Protestantismus und politische Romantik (1932), GW II, p. 217). 365)

69. Die Sozialistische Entscheidung, Postdam 1933 (GW II, pp. 219-

70. R. MAY, Paulus A personal Portrait; p. 9. 
los Estados Unidos, hacia donde partió con su esposa Hannah y su hija Erdmuthe (1933).

MAGisterio americANO-- (1933-1965).- La estancia de Tillich en América es más conocida y más divulgada, dada la cantidad dé comentarios americanos al pensamiento de nuestro autor. Nosotros nos reduciremos a señalar los pasos más importantes.

Una cosa queda clara: los primeros quince años de Tillich en América resultaron para él muy duros. La dificultad del idioma, la diferente situación política y religiosa, y la necesidad dé traducir los esquemas filosóficos y teológicos alemanes a los esquemas de pensamiento del nuevo mundo, supusieron una enorme labor y un esfuerzo difícil de imaginar. Rollo May nos describe el desarrollo de las primeras conferencias de Tillich en New York, con la simple asistencia de unos veinte estudiantes y algunos miembros de la Facultad, a pesar de lo atractivo de los títulos: "Implicaciones espirituales del psicoanálisis", "Significado religioso del arte moderno... ${ }^{71}$. De ahí que recuerde con afecto y agradecimiento la amistad de los otros colegas alemanes emigrados; la invitación que le hicieron el "Grupo de Discusión Teológica", así como la "Sociedad Americana de Teología" y el "Club Filosófico" de la Columbia University. En estos círculos de cultura, Tillich tuvo la oportunidad de conocer a fondo la teología y la filosofía americanas ${ }^{72}$.

Son años dedicados plenamente al mundo académico y a la comunidad del Union Theological Seminary. En este ambiante encontró Tillich el calor humano para seguir viviendo. El Seminario significó para él "una comunidad de vida y de trabajo" en contraposición con el individualismo académico alemán; "un puente entre los continentes" dado el intercambio no sólo teológico sino también cultural y político existente, merced a los numerosos personajes que por alli pasaban; "centro de la vida americana" dadas las actividades que desarrollaba. Pero lo que Tillich recuerda con verdadero cariño es que el Seminario ofrecía también un "lugar de culto común" en donde se vivía la experiencia eclesial y en donde él frecuentemente hablaba a los alumnos.

La situación americana le fuerza a abandonar una parcela del

71. R. Max, Paulus. A personal Portrait, p. 3.

72. The Theology of Paul Tillich, pp. 17-18. 
campo intelectual alemán que giraba en torno a la "Filosofía de la Religión", dada la imposibilidad de mantener contacto frecuente con los escritores, poetas y artistas. Gracias a ello se entrega de lleno a la labor docente teológica, superando de lleno el provincialismo científico alemán y abriéndose a los grandes horizontes de otras cuituras. A superar este provincialismo alemán le ayudó la triste experiencia hitleriana: "Aquello que verdaderamente nos llamaba la atención en el momento de nuestra emigración no fue tanto su tiranía (de Hitler) y su brutalidad como el nivel inimaginablemente bajo de su cultura. Pronto nos dimos cuenta que si la cultura alemana había podido producir un fenómeno como Hitler, es que alguna cosa no marchaba bien en esa cultura... Durante mucho tiempo ni mis amigos ni yo osamos hablar sobre lo que significó la grandeza alemana del pasado. Si Hitler es el producto de aquello que nosotros creíamos era la verdadera filosofía y la única teología, habria que afirmar que ambas eran totalmente falsas" "3.

Pronto comprendió que la teología americana no podía presumir de grandes investigaciones históricas y dogmáticas, sino que el punto principal de su influencia era la ética social, una especie de realismo social cristiano que, sin llegar a identificar el mensaje evangélico con un determinado programa político, permite a las Iglesias estar presentes en los diversos problemas de la sociedad. El peligro era la carencia de dirección vertical, así como en Europa el peligro fue siempre la carencia de dirección horizontal. No será aventurạdo afirmar que la gran aportación tillichiana a la Iglesia del nuevo mundo ha sido la de dar profundidad a su teología, ofreciendo una formulación nueva del mensaje.

Conviene resaltar de manera especial el interés queTillich demuestra en América por la psicología profunda. Interés que se fundamenta en la gran afinidad y relación que tienen la comprensión psicoterapeútica y teológica del hombre. Las razones de este interés las encuentra en la importancia que se daba en el Union Seminary a esta ciencia, así como su participación en un seminario sobre "Religión y salud" en la universidad de Columbia. Junto a esto hay que destacar la amistad que le unió durante muchos años con los más cualificados representantes del psicoanálisis y de la psicoterapia. Las

73. Theology of Culture, p. 163-164. 
producciones teológicas de estos años demuestran esta influencia, ayudándole a redescubrir la importancia del culto como valor formativo religioso, la importancia del elemento sacramental y los valores conservados por la Iglesia romana en lo que él llama la "verdadera substancia católica". "El redescubrimiento del inconsciente en la psicología médica y la intuición de los estímulos inconscientes en el alma de las masas me dio la clave para comprender el problema fundamental del culto protestante. La pérdida de los : sacramentos y de los símbolos corresponde en el Protestantismo al exclusivo relieve que asume el centro de la personalidad" "74. Esto nos explica la importancia que Tillich concede en su escritos al análisis de la existencia humana tal como es vista por la moderna psicología, llegando a hacer la siguiente afirmación: "No creo sea posible elaborar actualmente una doctrina cristiana del hombre, especialmente una doctrina cristiana del hombre cristiano, sin usar el inmenso material ofrecido por la psicología profunda" ${ }^{75}$.

LA PRODUCción TILLIChIANA.- Antes de concluir esta breve reseña acerca del profesorado de Tillich, creemos conveniente ofrecer, en arriesgada síntesis, un panorama de la producción literaria de nuestro autor. Los títulos de libros y artículos producidos por Tillich desbordan la posibilidad de enumeración. Son más de cuatrocientos. Intentando dar claridad, podríamos dividir, siguiendo a Nicholls, la literatura de Tillich en tres grandes apartados:

a) Escritos de "teologia de la cultura", que abarca todos aquellos problemas que preocupan al hombre en su relación con la comunidad humana en que vive y con la historia. Gran parte de esta producción gira en torno al Socialismo Religioso y sus contornos. Son los escritos de juventud y de la primera madurez. Terminan prácticamente con la segunda guerra mundial.

74. The Protestant Era, p. xix- $\mathrm{xx}$.

75. The Theology of Paul Tillich, p. 19. La influencia de estos elementos de la psicologia profunda la encontramos en algunos ensayos de Tillich, con una aplicación directa tanto al examen de la existencia humana como al mundo de lo sacramental. Cfr. "The permanent Significance of the Catholic Churh for Protestantism", en Protestant Digest, 10 (1941), pp. 23-31 (GW VII, pp. 124-132); "Challenge to Protestantism", en The Protestant, 4 (1942), pp. 1-4; asi como diversos pasajes de The Protestant Era y The Courage to Be (1952). Según confesión del propio Tillich, este último libro viene a ser la respuesta ontológico-religiosa a la tesis de su discípulo R. May: The Meaning of the Anxiety. 
b) Sermones, que abarcan esencialmente sus tres tomos de homilias: The Shaking of the Foundations (1948), The New Being (1955) y The Eternal Now (1963). Son obras dirigidas al gran público, con un lenguaje sencillo y penetrante. Los dos primeros tomos contribuyeron notablemente a la popularidad de Tillich a nivel de masas.

c) Escritos propiamente teológicos, de carácter académico. Entre ellos resalta de manera especial su Systematic Theology, Dynamics oi Faith (1957) y Love, Power and Justice (1954), así como algunas publicaciones póstumas que contienen sus cursos sobre historia de la teología: A History of Christian Thought ${ }^{76}$.

La Systematic Theology es la obra clave de Tillich y la base fundamental para una auténtica comprensión e interpretación de todo su pensamiento. Es la obra de su vida. Aunque su lectura resulta en ocasiones un tanto difícil y exige máxima concentración, se hace necesaria. No dudamos en pensar que gran parte de las criticas ligeras y de los juicios radicales hechos sobre Tillich descansan principalmente en haber leído solamente algunos de sus escritos secundarios. La obra le costó a Tillich casi cuarenta años de reflexión. Comenzó en Marburg en 1925, apareciendo el primer volumen en 1951, el segundo en 1957 y el tercero en 1963. El conjunto de los tres volúmenes forman un entarimado perfecto en plan de sistema, no de suma teológica, que exige una referencia al todo cuando se quiere tratar algún punto concreto. Sus cinco partes reflejan el contenido general: 1. ${ }^{a}$ Razón y Revelación; 2. ${ }^{a}$ Ser y Dios; $3{ }^{a}$ Existencia y Cristo; 4. ${ }^{a}$ Vida y Espiritu; 5. Historia y Reino de Dios. Como se ve, cada una de las partes abarca dos secciones. La primera sección: Razón - Ser - Existencia - Vida -Historia, implica el estudio y el análisis fenomenológico de la existencia del hombre moderno, a escala individual y social, con toda su carga de tragedia, alienación, ruptura y pecado. Este hombre presenta la gràn pregunta que es él mismo. En este análisis Tillich echa mano de todos sus conocimientos filosóficos, psicoanalíticos e históricos, resultando imposible el encuadrarlo dentro de una determinada corriente de pensamiento. La segunda sección: Revelación-

76. W. Nicholis, Systematic and Philosophical Theology, Harmondsworth 1971, pp. 238-239. 
Dios- Cristo-Espiritu-Reino de Dios, no es otra cosa que la respuesta del Dios que se revela, ofreciendo al hombre la posibilidad de una realización plena humana, mediante la reunión consigo mismo, con la naturaleza y con el mismo Dios; realización que tiene su punto culminante en la figura de Jesús como el Cristo, el nuevo Ser y que se perpetúa en la Iglesia mediante la presencia del Espíritu. Esta respuesta no viene nunca deducida de la pregunta, sino de la fe cristiana recibida en una experiencia reveladora y transmitida por la tradición eclesial. Pero siempre es el hombre el que recibe la fe como don de Dios. De ahí que tenga que comenzar por el estudio del hombre, dado que éste es el actor más cercano a su propia historia y el receptor de la Palabra de Dios. Viene a ser una vía media, de tipo apologético, que aúna los grandes valores de las diversas corrientes teológicas. Ya en 1948 escribía Tillich acerca de su intento teológico: "Deseo hacer una breve digresión para indicar cuál es mi postura ante las dos tendencias principales de la teología moderna: la teología llamada 'dialéctica' en Europa y 'neo-ortodoxa' en América, y la teología llamada 'liberal' en Europa y a veces 'humanista' en América. Mi teología se puede entender como un esfuerzo por superar el conflicto entre estos dos tipos de teología. Pretende demostrar que la alternativa expresada en estas denominaciones no es válida; que muchos de los enunciados contradictorios son expresiones de una etapa superada del pensamiento teológico; y que entre tantas concepciones e interpretaciones nuevas de la vida, el principio protestante prohibe tanto la ortodoxia antigua y nueva como el antiguo y nuevo liberalismo" 7 .

Los últimos años de su existencia fueron para Tillich un paseo casi triunfal, ya que se le reconocía como el teólogo de América. A pesar de los achaques físicos, mantuvo un vigor mental extraordinario hasta los últimos días, siguiendo un ritmo de trabajo difícilmente igualable. A sus setenta y ocho años, durante el último curso académico, daba una clase semanal y dirigía dos seminarios de tres horas semanales cada uno de ellos. El mismo Mircea Eliade, que dirigió con Tillich un seminario conjunto sobre Historia de las religiones y Teologia Sistemática, declara: "No era solamente el espectáculo maravilloso de un viejo maestro de setenta y ocho años que,

77. The Protestant Era, p. xxii-xxiii. 
después de tres horas de discusión, mantenía la atención más fresca y viva que muchos miembros del seminario, incluido yo mismo; era sobre todo la experiencia casi carismática de estar ante una mente creadora en un auténtico proceso de creación" ${ }^{78}$.

A pesar de todo, Tillich hubo de abandonar este mundo sin poder cumplir dos deseos: traducir directamente al alemán su Systematic Theology y el refundir esta misma obra teniendo en cuenta la historia de las religiones. Su trabajo se vio recompensado con numerosos homenajes "recibiendo el título de Doctor honoris causa por más de diez universidades americanas, así como de las de Berlín, Halle y Glasglow. Entre otros honores concedidos merecen ser recordados sobre todo: la Grosses Verdienstkreuz - la mayor condecoración alemana- por manos del presidente de la República Federal Alemana, la medalla de Goethe de la ciudad de Frankfurt y el premio Goethe de la ciudad de Hamburg" ${ }^{79}$.

78. M. Eliade, "Paul Tillich and the History of Religions", en The F'uture of Religions, New York 1966, p. 32-33.

79. B. Mondin, Paul Tillich e la transmitizzazione del Cristianesimo, Torino 1967 , p. 35 . 


\section{EL SISTEMA}

Tillich, al igual que otros grandes pensadores de su tiempo, tiene conciencia de estar en el final de una época y en el comienzo de otra nueva. Esta nueva época de la historia viene fechada con el estallido de la primera guerra mundial en 1914. El hasta entonces triunfante idealismo viene reemplazado por una existenica en conflicto, en desesperación y en angustia. La existencia en la historia aparece como el punto central de la reflexión humana.

Dentro del campo teológico protestante, la nueva época significa la lucha declarada contra el liberalismo teólogico, de carácter moralista o historicista, y el nacimiento de la neo-ortodoxia que redescubre existencialmente los grandes valores del evangelio. El problema radical se presenta asi: ¿qué significa el cristianismo para el hombre de hoy? ¿Cómo hacer presente la esencia cristiana al hombre moderno?

Barth opta por una mirada continua al cielo, proclamando a Dios por encima del mundo, redescubriendo su divinidad como "totalmente Otro", pero a la vez corre el peligro de perder de vista la historia concreta. Bultmann optará por un Dios que esté delante de (gegenüber), llamando al hombre a la decisión existencial, con el peligro de convertir el evangelio de la gracia en simple evangelio de la exigencia. Tillich tiende una mirada a la tierra y a la historia, queriendo encontrar la huella de Dios en todo lo que existe; no como ley lanzada desde arriba sino como algo que toca de cerca al hombre y le concierne de manera última. El "todo es vuestro, vosotros sois de Cristo y Cristo es de Dios" le ofrece el camino para encontrar en la historia el logos universal, convertido en realidad y gracia en el Logos hecho carne, Jesús como el Cristo, cuya misión será la de desvelar al hombre el misterio de su vida y reunificarlo consigo mismo y con Dios. El acentuar la presencia de Dios en el hombre siempre ha llevado consigo el peligro y la sospecha de cierto panteísmo; peligro y sospecha que se da en la obra y en el pensamiento de Tillich.

Con este transfondo genérico, podemos decir dos palabras 
acerca del sistema teológico de Tillich y de su intento cristiano de ofrecer una nueva formulación del mensaje al hombre de hoy ${ }^{80}$.

EL MÉroco.- La teología debe ser "la organización metodológica de los elementos de la fe cristiana" ". La teología puede tener varias vertientes: histórica, sistemática y práctica. La teología sistemática será "la formulación de la doctrina tradicional para nuestra situación actual" \&. Este esquema tan sencillo le ofrece a Tillich la posibilidad de presentar su método teológico; que no es otro que la forma de unir el mensaje siempre eterno y la situación concreta de la existencia, de manera tal que no se eliminen entre sí.

La teología sistemática no será, pues, una disciplina de tipo histórico, sino esencialmente un trabajo constructivo, dentro del seno de la Iglesia, con la única finalidad de exponer e interpretar los contenidos doctrinales del mensaje como respuesta a la situación concreta del hombre y a su pregunta existencial. Este es el método de la correlación, cuya explicación exige algunas matizaciones.

a) El mensaje. Se trata del mensaje siempre eterno del evangelio que proclama la divinidad de Dios ante el abuso de su nombre por parte del hombre. El contenido esencial de la teología será siempre el mismo: lo Incondicional y sus expresiones, Jesús como el Cristo y los símbolos cristianos. En este sentido la teología y el cristianismo tienden a identificarse. Pero la teología no es el mensaje, sino la formulación del mismo en un momento de la historia. $Y$ este momento de la historia lo hace el hombre; de ahí que resulte imposible el realizar una teología incondicionada dentro del tiempo. "Dios, en su naturaleza abismal, no depende de modo alguno del hombre; en su manifestación al hombre depende de la manera cómo el hombre recibe su manifestación". ${ }^{83}$. He aquí la justificación de la nueva formulación tillichiana, al menos en su intención, para conseguir decir al hombre la verdad sobre Dios y la verdad sobre sí mismo.

80. La exposición más completa de lo que debe ser la teología sistemática es la hecha por el mismo autor en el volumen primero de su Systematic Theology (1951), pp. 3-68, en donde estudia detenidamente la naturaleza, la organización, el método y la estructura del sistema que desarrollara a travès de toda la obra.

81. Systematic Theology (ST) I, p. 28.

82. ST I, p. 32 .

83. ST I, p. 61 . 
Tillich es consciente de que el vocabulario de la Iglesia está alejado de la situación histórica; y que como consecuencia de esto los hombres se apartan de la predicación porque no la entienden. Su teología quiere servir a la predicación cristiana y por eso inten ta un nuevo lenguaje para la traducción del mensaje: "es necesario salvar el lenguaje antes de salvar las almas", decia en una conferencia en Frankfurt. Se niega a aceptar toda crítica que no parta de este presupuesto. "Yo no puedo considerar como valiosa la crítica de quienes se limiten a insinuar que he abandonado la substancia del mensaje cristiano porque ha utilizado una terminología que conscientemente se aparta del lenguaje biblico o eclesiástico. Por mi parte, sin tal divergencia del lenguaje, no hubiese creído que valía la pena desarrollar un sistema teológico para el mundo de nuestros días" 84 .

b) La situación. El método procede analizando la situación humana que provoca preguntas existenciales; y a la vez demostrando que el contenido del mensaje es la respuesta a tales preguntas. Ambos aspectos deben estar siempre presentes en la labor del teólogo sistemático. Dejar en el olvido a cualquiera de ellos conduce necesariamente o a la diástasis bar'hiana que niega todo punto de encuentro entre Dios y la historia, o bien al naturalismo teológico liberal que identifica Dios y el mundo.

La relación humano-divina es correlación. En toda experiencia religiosa aparece el lado objetivo de Dios que se revela y el lado subjetivo del hombre que recibe la revelación. Si falta Dios que actúa no hay nada de objetivo; y si el hombre no recibe al Dios que se revela, la revelación cae en el vacío. El hombre, receptor del don de Dios, va haciendo su vida a través de la historia, creando siempre nuevas situaciones. La situación a la que hay que atender, según Tillich, es "la interpretación creadora del hombre en todos los dominios de la cultura". La filosofía, el arte, la novela, la psicología, la psicoterapia y la sociología ofrecen los materiales para la comprensión de la situación humana en un momento determinado de la historia.

c) La respuesta. "El mensaje cristiano nos proporciona las

84. ST II, p. vi. 
respuestas a las preguntas que se hallan implícitas en la existencia humana. Tales respuestas están contenidas en los acontecimientos reveladores sobre los que se fundamenta el cristianismo, y la teología sistemática los toma de las fuentes, a través del elemento mediador y según la norma. Su contenido no puede deducirse de las preguntas, es decir, de un análisis de la existencia. Las respuestas son "dichas" a la existencia humana desde más allá de ella. De lo contrario no serian respuestas, ya que la pregunta es la misma existencia humana" ${ }^{85}$. La pregunta existencial sobre el hombre y la respuesta reveladora tienen entre si una cierta dependencia e independencia. Esta interrelación mutua entre pregunta y respuesta constituye la espina dorsal de la estructura del sistema teológico de TiIlich. "Existe una mutua dependencia entre la pregunta y la respuesta. Con relación al contenido, las respuestas cristianas dependen de los acontecimientos reveladores en los que aparecen; con relación a la forma, dependen de la estructura de las preguntas a las que responden. Dios es la respuesta a la pregunta implicita en la finitud humana. Esta respuesta no puede deducirse del análisis de la existencia" . Es decir, según Tillich las respuestas dependen de los acontecimientos reveladores en su contenido, pero dependen de la estructura de la pregunta en su forma.

El examen del método de correlación lleva consigo el análisis de otros puntos esenciales en el sistema: las fuentes de la teología, el elemento mediador y la norma teológica.

Fuentes de la teología.- Según Tillich, el cristianismo se fundamenta en el acontecimiento histórico de Jesús como el Cristo, Logos encarnado, y en el reconocimiento como tal por aquellos que le acogen y le proclaman. Tal acontecimento revelador y tal acogida se encuentran descritos en la Biblia. La Biblia aparece, por tanto, como la fuente fundamental de la teología sistemática, ya que es el documento original que "transmite los testimonios originales de qŭienes participaron en los hechos reveladores"; hechos que fundamentan la Iglesia cristiana. El acontecimiento revelador final es la manifestación de Jesús como el Cristo; revelación que se da mediante el 'Cristo a sus discípulos. Los escritores bíblicos participan de es-

85. ST I, p. 64

86. ST I, p. 64 . 
tos acontecimientos reveladores, de los cuales son testigos. En este sentido los escritores bíblicos están inspirados, ya que aceptan a Jesús como el Cristo, el Nuevo Ser que ofrece nueva dimensión y significación a la vida del hombre. Aceptando y participando en la nueva realidad del Cristo como Nuevo Ser, la Iglesia acepta la Biblia como documento originario y fundamental de la experiencia reveladora.

La teología no es el acontecimiento revelador, ni la experiencia reveladora. La teología es una reflexión orgánica sobre el mensaje, pero no es el mensaje mismo. La interpretación teológica es "un acto de la Iglesia y de los miembros de la Iglesia". Es cierto que la teología debe basarse en la revelación final, cuya fuente fundamental es la Biblia como documento originario; pero la teología ejerce su función dentro de la Iglesia y por eso ha de contar con la tradición eclesial como fuente secundaria de su reflexión. El teólogo actúa dentro de la vida concreta de su Iglesia, que expresa sus contenidos de fe y su experiencia reveladora en la liturgia, los himnos y los sacramentos. El círculo teológico en que debe vivir el teólogo abarca la experiencia personal de su fe, la valoración tradicional de las doctrinas que le ofrece su Iglesia y el compromiso de su vida al servicio del mensaje y de la situación ${ }^{87}$.

El ELEMENTo MEdiador.- ¿De qué modo recibe el teólogo este material de las fuentes de la revelación? La respuesta de Tillich es clara: mediante la experiencia existencial del gran acontecimiento de Jesús como el Cristo. "La experiencia no es la fuente de la que proceden los contenidos de la teología sistemática, sino el medio a través del cual los recibimos existencialmente" ${ }^{88}$. No se trata, como en Schlaiermacher, de deducir los contenidos de la fe de la "conciencia religiosa" del cristiano. El acontecimiento Jesús de Nazaret se da en la historia. Se trata de una relación existencial con la Verdad, de una experiencia cristiana vivida, a travếs de la cual la Biblia nos habla y podemos recibirla.

La experiencia cristiana no es la fuente de la teología, como pretenden los "entusiastas evangélicos", sino solamente el medio,

87. ST I, pp. 34-40; Cfr. A. R. Dulles, "Paul Tillich and the Bible", en Paul Tillich in Catholic Thought, London 1965, pp. 109-132.

88. ST I, p. 42. 
el instrumento mediante el cual el teólolgo recibe el mensaje y sus contenidos. De esta forma se cierran las puertas a todas posibles revelaciones que intenten sobrepasar $u$ oponerse a la revelación central. Tal experiencia implica una participación en la realidad del Cristo. Y solamente se puede captar esa realidad si se participa en ella de alguna manera. Esta participación es experiencia religiosa. "Es el Espíritu divino el que da testimonio en nosotros del mensaje bíblico" ${ }^{83}$. La experiencia no crea nuevas revelaciones en nosotros, sino que recibe el acontecimiento revelador. Cualquier intento de subjetivismo religioso que intente rebasar los límites de Jesús como el Cristo ha de ser rechazado. "La teología cristiana se fundamenta en el acontecimiento único de Jesús el Cristo, acontecimiento que, a pesar de su significación infinita, sigue siendo este acontecimiento $y$, como tal, constituye el criterio de toda experiencia religiosa. Este acontecimiento es previo a la experiencia y no derivado de ella: Por consiguiente, la experiencia lo recibe, pero no lo crea" ${ }^{90}$.

EL Criterio teológico.- El uso de las fuentes de la teología, juntamente con el elemento mediador, exige un criterio o una norma a la cual someterse. La norma debe ser "la expresión del encuentro de la Iglesia con el mensaje cristiano". A través de la historia, la Iglesia ha formulado diversas normas o criterios teológicos que corresponden a la acentuación de una faceta concreta del mensaje, y que, en un momento determinado, ofrecen en respuesta a las necesidades eclesiales. Las diversas normas aparecidas en la historia, consciente 0 inconscientemente, no se excluyen entre sí ni pueden excluirse, ya que se trata de formulaciones del mensaje bajo un aspecto : esencial. "Mientras para la primitiva Iglesia griega la norma fue la liberación del hombre finito de la muerte y del error por la encarnación de la vida inmortal y de la verdad eterna, para la Iglesia romana fue la redención del pecado y de la división por el sacrificio real y sacramental del hombre-Dios. Para el protestantismo moderno la norma era la imagen del Jesús "sinóptico", como representante del ideal personal y social de la existencia humana; y para el protestantismo reciente ha sido el mensaje profético del Reino de

89. ST I, p. 45 .

90. ST I, p. 46. 
Dios en el Antiguo y el Nuevo Testamento. Estos símbolos fueron los criterios conscientes o inconscientes con arreglo a los cuales la teología sistemática trató sus fuentes y juzgó la experiencia mediadora del teólogo" "

Tal norma se ha de inferir de la Biblia, como fuente fundamental de la teología, en un encuentro de la Iglesia con el mensaje. $Y$ dado que tal encuentro puede ser diferente en cada generación, habrá que concluir, según Tillich, que toda teologia debe optar en su momento por una norma concreta. Esta opción del teólogo no puede ser fruto de un puro subjetivismo, ya que el teólogo está. condicionado por la experiencia colectiva de la Iglesia en la que vive y a la que sirve. Esta Iglesia en que vive Tillich es el protestantismo moderno "que se caracteriza por la falta de una autoridad formal y la búsqueda de un principio material". En este contexto Tillich dice que la norma por él presentada ofrece una diferencia de énfasis en relación a la norma de los reformadores, pero que "pretende salvaguardar la misma sustancia y presentarla bajo una forma más adecuada a la situación y a la fuente bíblica" ${ }^{22}$.

La norma que propone Tillich como respuesta del mensaje a la situación actual es el Nuevo Ser. "No es exagerado decir que hoy el hombre experimenta su situación actual en términos de ruptura, de conflicto, de autodestrucción y de desespero en todos los sectores de la vida. Esta experiencia se expresa en las artes y en la literatura, se conceptualiza en la filosofía existencial, se actualiza en las divisiones políticas de todas clases, y es analizada por la psicología del inconsciente. Ha dado a la teología una nueva comprensión de las estructuras trágico-demoníacas de la vida individual y social. La pregunta que surge de esta experiencia no es, como en la Reforma, la pregunta por un Dios misericordioso y por el perdón de los pecados; ni es tampoco, como en la primitiva Iglesia griega, el problema de la finitud, de la muerte y del error; ni es siquiera la cuestión de la vida religiosa personal o de la cristianización de la cultura y de la sociedad. Es la pregunta por una realidad en la que la auto-alienación de nuestra existencia esté superada, una realidad de reconciliación y de reunión, una realidad de creatividad, de significación y de esperanza. Llamaremos a esta realidad el "Nuevo Ser", términos cu-

91. ST I, p. 47-48.

92. ST I, p. 49 . 
yos presupuestos e implicaciones sólo pueden explicarse a través de todo el sistema. Se fundamenta en lo que Pablo llama la "nueva creación" y hace referencia al poder de superar las divisiones demoniacas de la "vieja realidad" en el alma, en la sociedad y en el universo" ${ }^{93}$.

El criterio o la norma teológica del sistema teológico de Tillich es el Nuevo Ser. Este Nuevo Ser se manifiesta en Jesús como el Cristo, el nuevo eón que introduce en el mundo y en la historia la "nueva creación". "Si se me pidiera resumir en dos palabras el mensaje cristiano para nuestra época, yo diría con Pablo: es el mensaje de la "nueva creación" ${ }^{94}$. Tal norma puesta por Tillich intenta un doble objetivo: mantenerse fiel al mensaje bíblico y responder a los problemas de la existencia actual. La teología no puede huir del tiempo, por más que se lo proponga. Su contenido original es el mensaje bíblico, su lugar de nacimiento es la Iglesia, su objetivo es juzgar la experiencia cristiana y servir a la vez de criterio para el uso de la Biblia y del material de la historia de la Iglesia.

Tillich es consciente de que su sistema no es una panacea universal, y es consciente también de que su método es tan ambiguo como lo es la misma teología. "La revelación no nos es dada como un sistema". La teología no es el mensaje, sino la formulación del mismo. Y por más afán de pureza con que se quiera expresar, estará siempre condicionada por la historia. "El teólogo sistemático puede, pues, interpretar bajo una forma sistemática lo que transciende todos los posibles sistemas, la auto-manifestación del misterio divino": El hogar del teólogo será la lglesia, en donde se perpetúa en el tiempo - de forma sacramental- la realidad del NUEVO SER: JESUS COMO EL CRISTO.

Alfonso GaRRIDO SANZ

93. ST I, p. 49 .

94. The New Being, New York 1955, p. 15

95. ST I, p. 68 . 